\title{
CHANGES IN BLOOD AND INTERSTITIAL FLUID RESULTING FROM SURGICAL OPERATION AND ETHER ANESTHESIA ${ }^{1}$
}

\author{
By JOHN D. STEWART AND G. MARGARET ROURKE \\ (From the Surgical Laboratories of the Harvard Medical School at the \\ Massachusetts General Hospital, Boston)
}

(Received for publication February 24, 1938)

Much attention has been given in the past to the study of changes in the blood produced by hemorrhage. Considerably less study has been devoted to changes in body fluid resulting from ether anesthesia, though such findings as elevation of blood sugar, increase in hydrogen ion concentration of the blood, and reduction in plasma bicarbonate, have been well established. The present work presents measurements of changes in quantity, as well as concentration, of certain components of body fluid as found in 16 patients subjected to the traumatizing factors of major surgical operations and to ether anesthesia. The time chosen for obtaining data to compare with the preoperative normal values was just at the end of operation, while the patient was still anesthetized. None of the patients studied showed evidence of more than mild shock or anoxemia during the study period.

\section{METHODS}

On the morning of operation, before administration of preanesthetic drugs, the fasting patient was weighed. Determinations were then made of plasma volume, body fluid "available for solution of thiocyanate" (1), hematocrit, plasma protein, serum protein and serum albumin. In addition, serum nonprotein nitrogen and serum sodium, potassium, chloride, and bicarbonate were measured. These determinations were repeated at the end of operation while the patient was still anesthetized and before parenteral fluid had been given. In most instances blood loss during operation was measured, using the method of Gatch and Little (2).

Plasma volume was determined by the technic developed by Gregersen and his coworkers (3), using the blue dye $\mathrm{T}-1824$, the serum concentrations being measured spectrophotometrically. Hematocrit readings were made by adding $4 \mathrm{cc}$. of blood to $1 \mathrm{cc}$. of 1.1 per cent sodium oxalate and centrifuging in hematocrit tubes until no further change in the reading occurred, precautions against loss of carbon dioxide being taken. Serum sodium was determined by the gravimetric method of But-

\footnotetext{
1 This work was made possible by grants from the William F. Milton Fund, Harvard University, and the Josiah Macy, Jr. Foundation.
}

ler and Tuthill (5); serum potassium by Fiske's modified cobaltinitrite method in which potassium is reprecipitated as potassium acid tartrate (6) ; serum chloride by Wilson and Ball's method (7); carbon dioxide content of the serum according to Van Slyke and Sendroy (8); total nitrogen by macro-Kjeldahl (9) on both oxalated plasma and serum; nonprotein nitrogen of serum by micro-digestion and nesslerization. Serum albumin was determined by the sodium sulfate method of Howe (10). From the total protein of the serum and the serum albumin, colloid osmotic pressure was calculated, using the nomographic formula of Wells, Youmans, and Miller (11). Oxygen capacity was determined on heparinized venous blood drawn without stasis and equilibrated with room air at room temperature (17).

Whole blood volume was calculated from plasma volume and hematocrit. The validity of this calculation rests on the questionable assumption that the cell-plasma ratio of venous blood is the same as that of blood in the capillary bed. It is probable that the capillary bed is relatively richer in plasma than is venous blood, owing to "axial streaming" of cells in the capillary flow (18). The computation is made, however, in view of the possible comparative significance of figures obtained in the same individual in a short period. Total hemoglobin is computed from oxygen capacity and whole blood volume.

Body fluid available for solution of thiocyanate, tentatively taken as extracellular fluid and comprising water of interstitial fluid, plasma, and red blood cells but not of cerebrospinal fluid, was measured by a modification Gregersen and Stewart (4) have made in the original technic of Crandall and Anderson (1). In this improved method the same sample of serum is used for spectrophotometric measurement of both the blue dye, T-1824, of the plasma volume method, and the thiocyanate. Sodium thiocyanate is injected intravenously and a disappearance curve is constructed by determining the plasma level at ten-minute intervals subsequently. The point at which the curve flattens out, usually reached in 20 to 30 minutes, is taken as the concentration in extracellular fluids after diffusion equilibrium has been established. In accordance with the suggestion of Lavietes, Bourdillon, and Klinghoffer (13) correction is made for the slightly higher concentration of thiocyanate in serum than in transudate fluids. The interstitial fluid values given in the table are computed by the following formula:

Interstitial fluid $=$ thiocyanate injected (serum concentration $\times$ blood volume) $100 / 110 \times$ serum concentration 


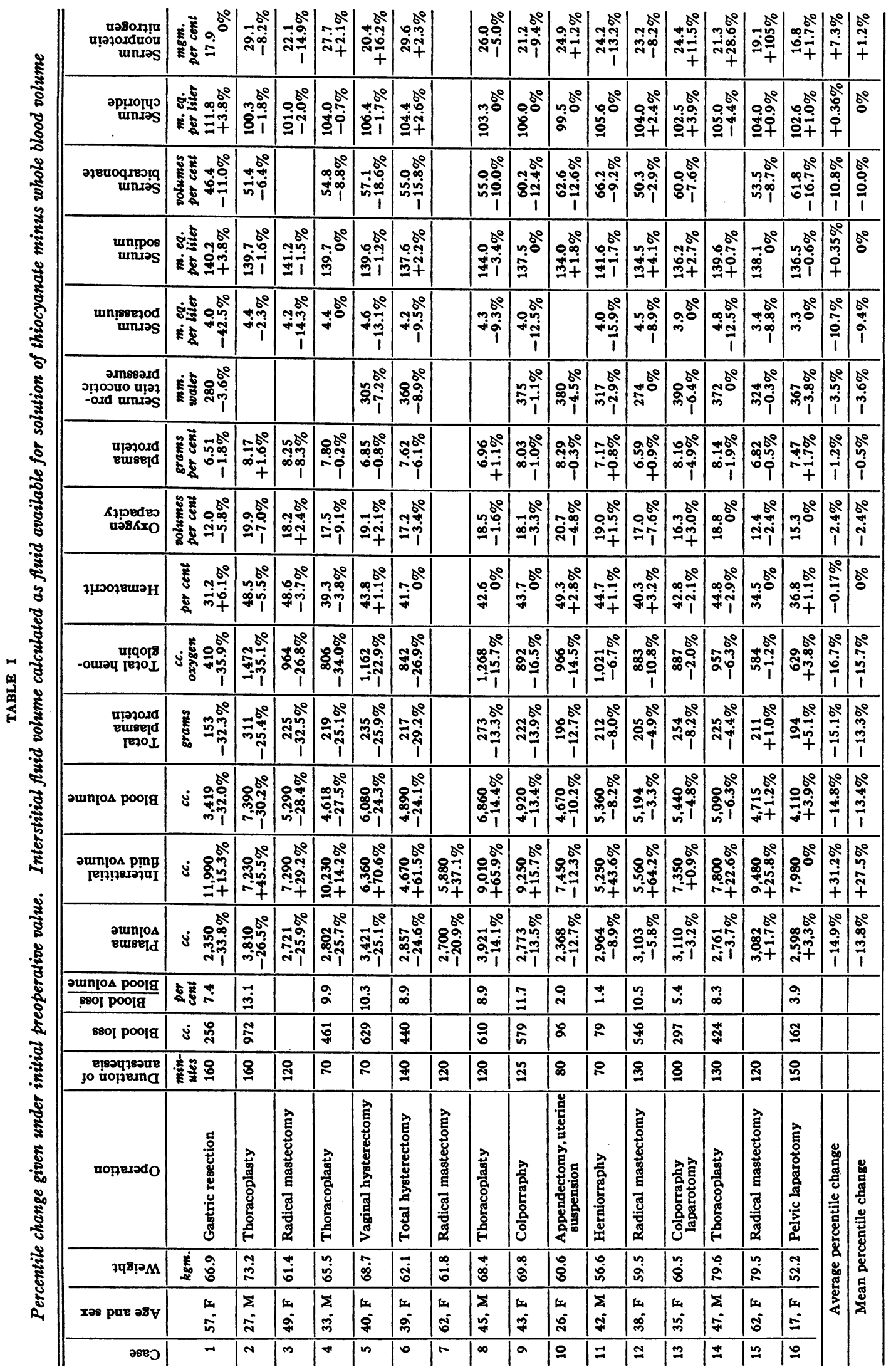


It is probably of little practical importance that such a calculation ignores the fact that concentration of thiocyanate by volume is lower in red blood cells than in plasma owing to the lower water content of the cells, and that thiocyanate is excluded from cerebrospinal fluid.

\section{DISCUSSION}

The measurements obtained in this study are given in Table I. In each instance the preoperative value is recorded and below it the percentile change from this value obtained from a measurement taken at the end of the period of operation and anesthesia. An outstanding fact described by these data is a considerable, and in several instances quite large, reduction of the volume of the blood without appreciable change in the physical or chemical character of the blood. In seven of the subjects, the reduction of total volume was more than 20 per cent, and the average for the series was 13.4 per cent. Hematocrit values were, however, found to be approximately normal and the structurally important components of blood plasma, namely, protein, sodium, and chloride, were found to be accurately sustained. The stability of these concentration values makes it clear that the reduction of blood volume is not the result of a process of dehydration. In other words, blood volume is reduced in toto and not by withdrawal of water. This reduction in most instances is, as may be seen in Table $I$, of much larger extent than is accounted for by the directly measured loss of blood caused by the operation. Since this finding rests on the dye method of measurement, it suggests that the quantity of actively circulating blood is reduced by a shunting of blood into some compartment of the vascular system which the dye does not rapidly enter. The reduction of blood volume was in most instances in this series much larger than McAllister and Gregersen (12) found in dogs as a result of etherization for 1 to 2 hours. This would be expected since to the effect of etherization is added a direct loss of blood and also the possibly contributing effect of tissue trauma.

The measurements of interstitial fluid volume obtained by the thiocyanate method describe a surprising and relatively large increase. The situation under study is one in which deficit in total body water must inevitably develop. Water released by metabolic processes will fall far short of water expenditure by the lungs, skin, and kid- neys. This increase in interstitial fluid volume is of much greater extent than change in plasma volume and is in the opposite direction. In view of the increase in volume of interstitial fluid indicated by the thiocyanate measurement one should expect either a reduction in the extracellular ions, sodium and chloride, or else an increase in the extracellular concentration of the dominantly intracellular ion, potassium. Neither condition is present. Therefore the apparent increase in interstitial fluid is open to question, since there is no reason to suppose there has occurred an uneven distribution of ions between plasma and interstitial fluid, beyond the relatively slight disproportion explicable on the Gibbs-Donnan theory. Nevertheless, the increase in interstitial fluid is so constant and large it deserves to be recorded. It is possible that in ether anesthesia the accessibility of certain fluid compartments, such as the intrathecal spaces, to the thiocyanate ion is increased.

Other measurements recorded in Table I may be mentioned briefly. The serum bicarbonate values show the quite well known moderate reduction. The concentration of potassium was found to fall considerably. We have no explanation to offer for this event, although in previous studies (14) increase of urinary potassium during operation and anesthesia has been found. Lowering of serum potassium concentration has been reported in dogs following experimental hemorrhage without anesthesia (15) and in dogs and guinea pigs following experimental etherization (16). The approximately normal serum nonprotein nitrogen is not surprising. According to the evidence of the measurements of oxygen capacity there is no appreciable disturbance of hemoglobin concentration.

In considering these data one cannot but be struck by the extraordinary way in which the composition of the blood is stabilized, despite large volume changes due to such stresses on the homeostatic mechanisms as hemorrhage, etherization, increased fluid loss through skin and lungs, and shifting changes in blood flow and cardiac output.

\section{SUMMARY}

In 16 patients undergoing major surgical operation under ether anesthesia lasting 1 to 3 
hours, changes in plasma volume and interstitial fluid volume were studied. In 13 of these cases blood loss at operation was measured.

Changes in hematocrit, oxygen capacity of venous blood, plasma protein, and colloid osmotic pressure of plasma protein were determined. Alterations in serum potassium, sodium, chloride, bicarbonate, and nonprotein nitrogen were measured.

From plasma volume, hematocrit, oxygen capacity and plasma protein were calculated blood volume, total circulating hemoglobin, and total circulating plasma protein before and after operation.

\section{CONCLUSIONS}

1. The trauma of surgical operation and ether anesthesia lowers plasma volume as determined by Gregersen's dye method, and increases interstitial fluid volume, as measured by the thiocyanate technic.

2. The reduction in plasma volume may be much greater than can be accounted for by hemorrhage.

3. Concentrations of serum potassium and bicarbonate are significantly reduced.

4. The tenacity with which concentrations of hemoglobin, and plasma protein, sodium, and chloride are held constant in the blood despite large volume changes is brought out.

5. The fallacy of assuming a quantitative relationship between changes in concentration of hemoglobin or plasma protein and changes in plasma volume is brought out.

The authors wish to thank Dr. James L. Gamble for helpful criticism in the preparation of this paper.

\section{BIBLIOGRAPHY}

1. Crandall, L. A. and Anderson, M. X., Estimation of the state of hydration of the body by the amount of water available for solution of sodium thiocyanate. Am. J. Digest. Dis. and Nutrition, 1934, $1,126$.

2. Gatch, W. D., and Little, W. D., Amount of blood lost during some of the more common operations. J. A. M. A., 1924, 83, 1075.

3. Gregersen, M. I., Gibson, J. J., and Stead, E. A., Plasma volume determination with dyes: errors in colorimetry; the use of the blue dye T-1824. Am. J. Physiol. (Proc.), 1935, 113, 54.

4. Gregersen, M. I., and Stewart, J. D. (In press.)

5. Butler, A. M., and Tuthill, Elizabeth, An application of the uranyl zinc acetate method for determination of sodium in biological material. J. Biol. Chem., 1931, 93, 171.

6. Unpublished method.

7. Wilson, D. W., and Ball, E. G., A study of the estimation of chloride in blood and serum. J. Biol. Chem., 1928, 79, 221.

8. Van Slyke, D. D., and Sendroy, J., Jr., Carbon dioxide factors for manometric blood gas apparatus. J. Biol. Chem., 1927, 73, 127.

9. Wong, S. Y., The use of persulphate in the estimation of nitrogen by the Arnold-Gunning modification of Kjeldahl's method. J. Biol. Chem., 1923, $55,427$.

10. Howe, P. E., The use of sodium sulfate as the globulin precipitant in the determination of proteins in blood. J. Biol. Chem., 1921, 49, 93.

11. Wells, H. S., Youmans, J. B., and Miller, D. G., A formula and nomogram for the estimation of the osmotic pressure of colloids from the albumin and total protein concentrations of human blood sera. J. Clin. Invest., 1933, 12, 1103.

12. McAllister, F. F., and Gregersen, M. I., The effect of ether anesthesia upon the plasma volume of dogs. Am. J. Physiol. (Proc.), 1937, 119, 363.

13. Lavietes, P. H., Bourdillon, J., and Klinghoffer, $K$. A., The volume of the extracellular fluids of the body. J. Clin. Invest., 1936, 15, 261.

14. Stewart, J. D., Unpublished data.

15. Stewart, J. D., and Rourke, G. M., Intracellular fluid loss in hemorrhage. J. Clin. Invest., 1936, 15, 697.

16. Robbins, B. H., and Pratt, H. H., Ether anesthesia: Changes in the serum potassium content during and following anesthesia. J. Pharmacol. and Exper. Therap., 1936, 56, 205.

17. Van Slyke, D. D., and Neill, J. M., The determination of gases in blood and other solutions by vacuum extraction and manometric measurement. I. J. Biol. Chem., 1924, 61, 523.

18. Smith, H. P., Arnold, H. R., and Whipple, G. H., Blood volume studies. VII. Comparative values of Welcker, carbon monoxide and dye methods for blood volume determinations; accurate estimation of absolute blood volume. Am. J. Physiol., 1921, 56, 336. 